\title{
Methods of determination of morphological indicators in hydrological calculations in the design of roads and road structures
}

\author{
Barno Salimova ${ }^{*}$, Abdukhaxxor Tulyaganov, Raykhan Khakimova, and Pokizakhon \\ Muslimova \\ Tashkent state transport university, Tashkent, Uzbekistan
}

\begin{abstract}
In solving the engineering problems in the practice of different specialties, in the design of roads and roads, structures, determining the physiographic conditions of the same regional areas: basin area (F), height $(\mathrm{Z})$, average square difference of basin height (s), slope (J), parameters such as the length of the main channel in the basin (L), the width of the maximum water flow in the basin $(\mathrm{V})$ and its depth (h), that is the determination of the calculated values of morphological indicators, performed using a large-scale map. It allows to estimate the amount of physical-geographical and morphological indicators, analyze their interrelationships, reveal the regions' physical-geographical laws, use them in hydrological calculations in the basin, and determine their values, to apply them in solving engineering problems.
\end{abstract}

\section{Introduction}

The following is a description of new approaches to determining the values of physical, geographical, and morphological indicators from the topographic map, the expression of their interrelationships.

Basin area $(F)$. The part of the earth's surface that forms a stream of atmospheric precipitation at the top of a projected structure in a river valley is called the catchment area (basin). A water dividing line is used to demarcate the area of the basin, i.e., the catchment area. The surface area is determined from large-scale maps, aerial photographs, field survey materials. In defining the catchment area on topographic maps, the dividing lines are drawn perpendicular to the horizontal (Figure 1a). In the field, data measured along the "theodolite path" passed through the water-separating peaks are used (Figure 1) [1, 2].

The height of the basin $(Z)$. The solution of geodetic engineering problems is determined by the fact that the average height of the basin (Excellent) in hydrological calculations is one of the main parameters (referred to in the literature as the average weight or height of a normal basin):

$$
Z_{x}=\frac{1}{F} \sum_{i=1}^{N} Z_{i} f_{i}
$$

\footnotetext{
* Corresponding author: naikon-09@mail.ru
} 
where: $F$ is the catchment area of the basin; $f_{i}-i f_{i}-i$ elevation area; $Z_{i}$ is the average of the height ranges $i$;
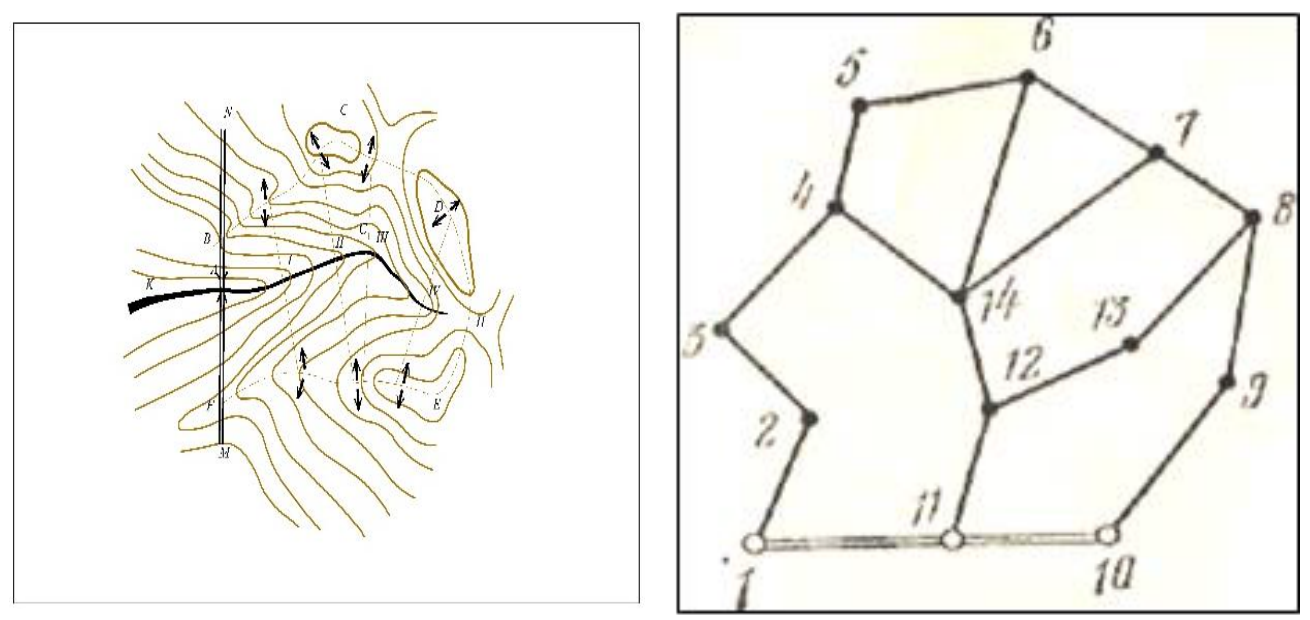

Fig. 1. View of the boundary of the catchment area of the artificial structure at point $A$ on the MN road in the Parkent valley (left) and the theodolite road (right) passing through the watershed line.

\section{Materials and Methods}

Water separation area passing through VSDNEF points with a dotted line; The numbers indicate the reference points $[3,4,5]$.

Basic square difference of pool height (s). The coefficient - s, which plays an important role in the formation of the flow, representing the length of the water basin along the vertical plane of the basin, is found from the following equation:

$$
\sigma_{z}=\sqrt{\frac{1}{F} \sum_{i=1}^{N}\left(z_{i}-z_{x}\right)^{2}\left(f_{i} .\right)}
$$

where: $i$ is area of elevation zones; The total number of $N$.

In cases where the calculation of this parameter is complicated, it is proposed to use an empirical expression based on the correlation of the basin height (Z) with (figure 2):

$$
\sigma=0.647 \ln (Z)+0.061, \quad r^{2}=0.629
$$




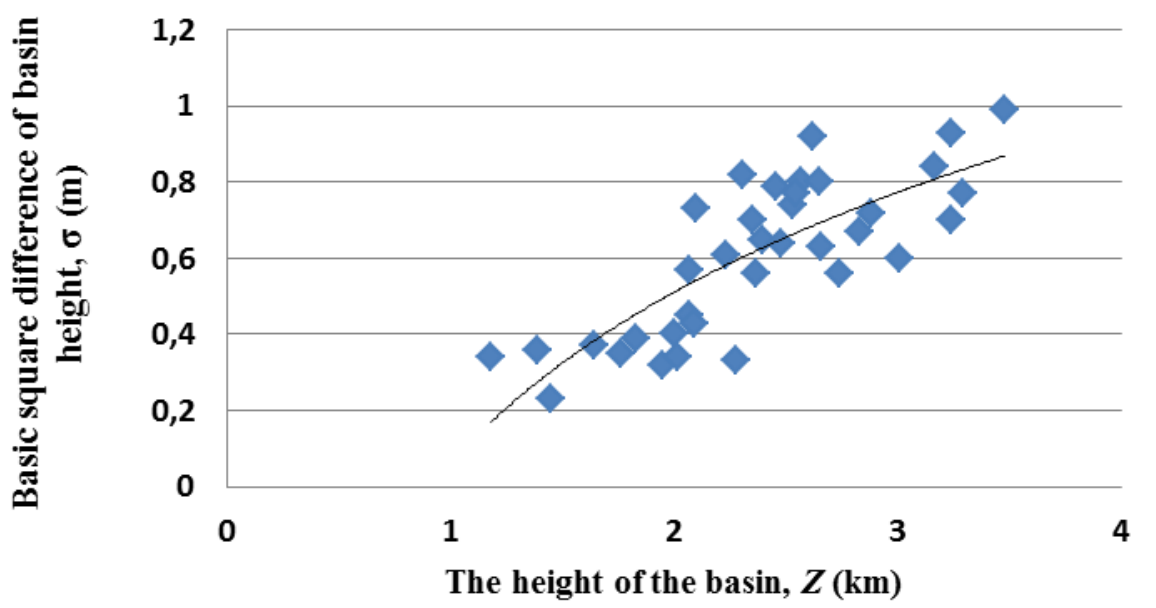

Fig. 2. Diagram of the relationship between the heights of small mountain basins of Uzbekistan and the average square difference of their heights

Calculation of point heights $(Z)$. Using a topographic map, we will focus on some engineering problems in the calculation of elevations and their solutions [6]:

If point $A$ (figure 3 ), whose height is to be determined, lies on a horizontal line, it is assumed to be equal to that horizontal line's height. $Z_{\mathrm{A}}=150 \mathrm{~m}$.

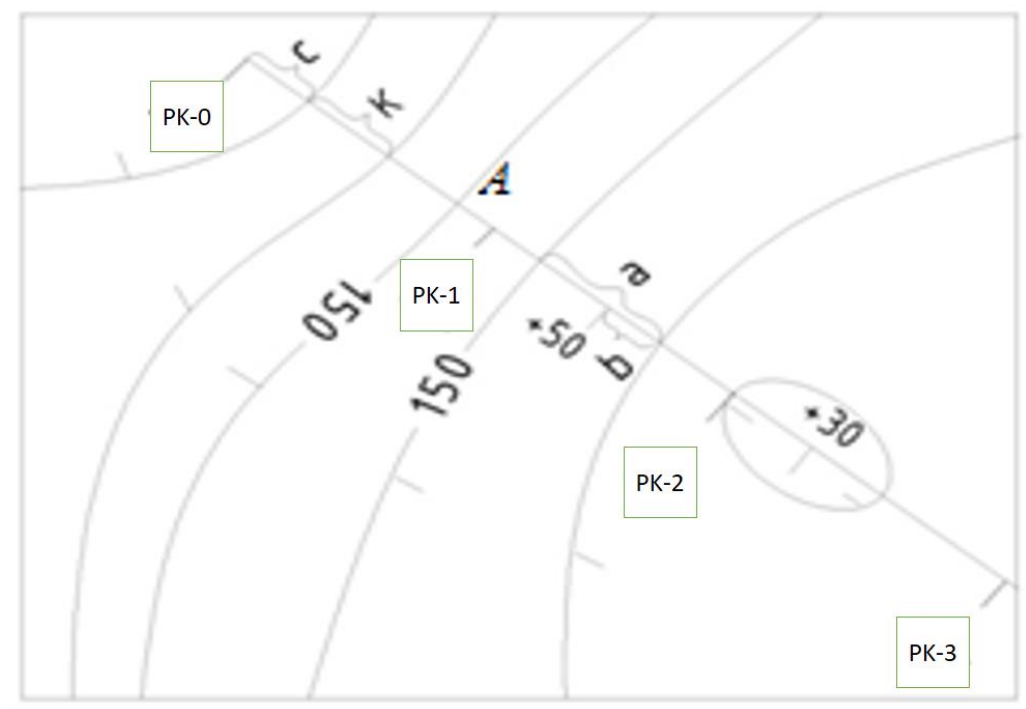




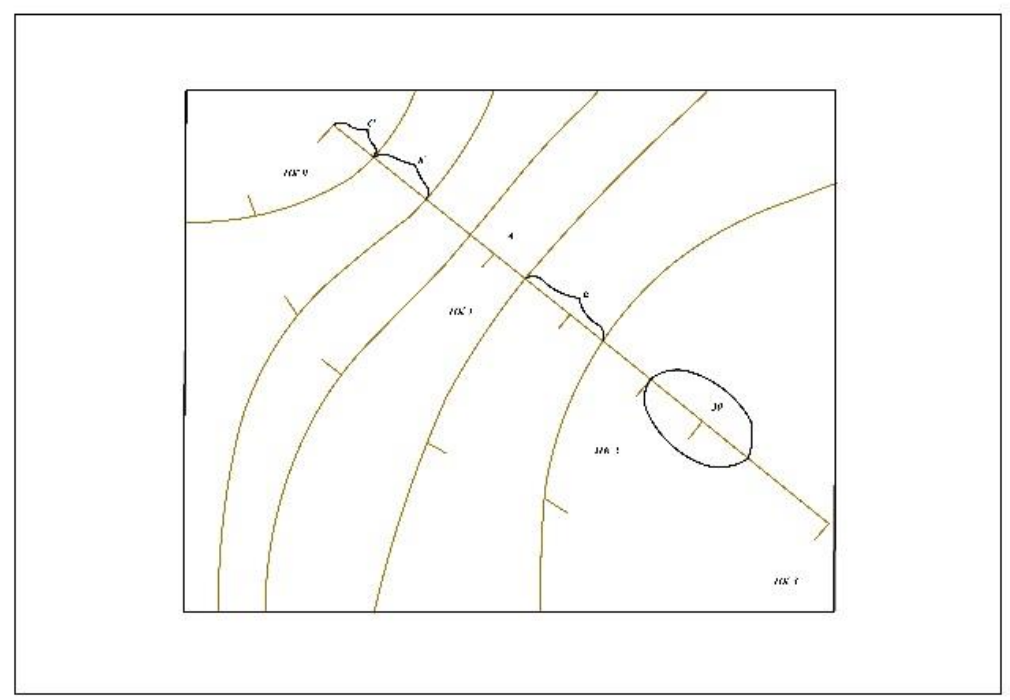

Fig. 3. Diagram of the appearance of points on the topographic map. In the picture PK0, PK1 ... picket points; A, $+50,+30$ height points to be determined; 150 - horizontal height.

Horizontals were conducted every $5 \mathrm{~m}$; Cutting height $h=5 m-P K+50$ located between the horizontal lines - the height of the point is determined by the interpolation method:

$$
Z_{+50}=Z_{g} \pm h_{1}
$$

where $\mathrm{Ng}$ is the height of the horizontal line; $\mathrm{h} 1$ is multiplication.

$$
h_{1}=(b / a) h
$$

The expressions $\mathrm{a}$ and $\mathrm{b}$ are the lengths perpendicular between the horizontal and the horizontal line along the same perpendicular to the picket point; $h$ is the cut height. - Calculations are performed on the closed horizontal line $(\mathrm{PK}+30)$ according to the following expression:

$$
Z_{+30}=Z_{g} \pm h / 2
$$

The following equation is used to determine the heights of points between two horizontal lines of the same height:

$$
Z_{P K}=Z_{\Gamma} \pm h / 4
$$

Extrapolation method is proposed when the point is in the corner of the map sheet:

$$
Z_{P K}=Z_{g} \pm h^{\prime}
$$

where $\mathrm{h}^{\prime}$ is the increment.

$$
h^{\prime}=\mathrm{c} / k \cdot h
$$

In expressions, $\mathrm{Z}$ is the height of the horizontal at the edge of the map; $\mathrm{s}$ is distance from horizontal to picket; $\mathrm{k}$ is the distance between the horizontal lines. 
Approaches to the calculation of hydro morphological parameters of the basin: the slope of the basin (J), the length of the basin (L), the width (V) and depth (h) of the basin at maximum water consumption and their derivations based on their interrelationships consider the example of dangerous pools. The slope of the river $(\mathrm{J})$. The slope of the river is determined by the method of geometric leveling in the field or by the relationships of the river slope based on the morphometric parameters of the basin (figure 4) [7-10]:

$$
J=\mathrm{k}_{\mathrm{J}} \frac{\sigma_{Z}}{L}=\frac{k_{J}}{k_{L}} \frac{\sigma_{Z}}{\sqrt{F}}
$$

or for small basins in the Adir region:

$$
J=\frac{0.0048}{F^{0.35}}
$$

where: $F$ is the area of the basin, determined from the map; $\frac{k_{j}}{k_{L}}$ it is recommended to assume that the coefficient of proportionality is equal to $1.79 ; \sigma_{Z}$ is the value of (3) is found from the expression.

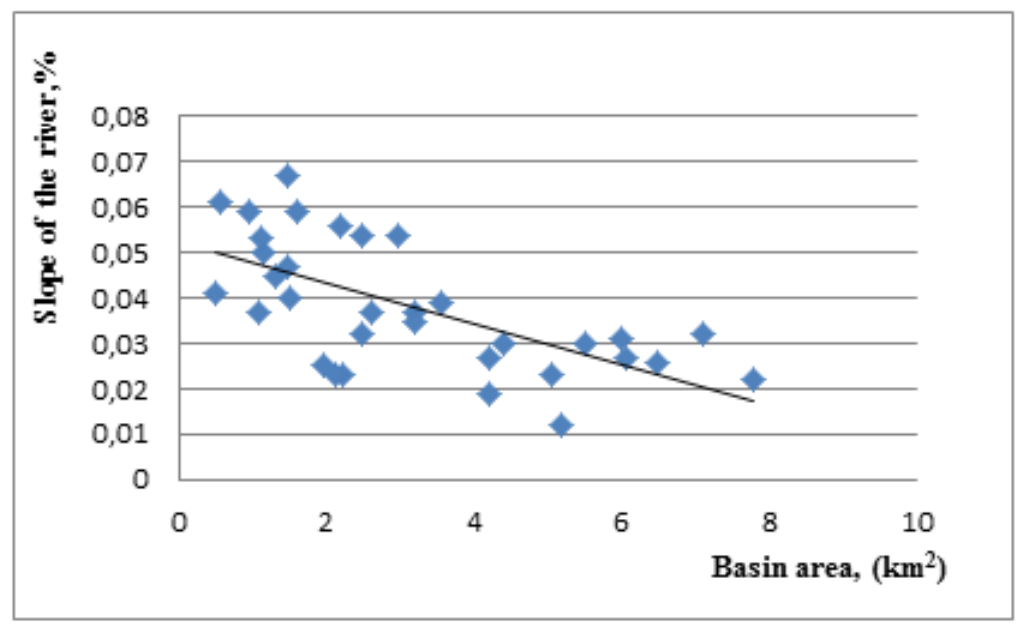

Fig. 4. The connection of the slope of the river with the areas of small basins in the Adir region $(r=0.532)$

Determining the length of the basin is described further. The method described below is used when using small-scale maps and when the basin in the basin is not clearly represented. One of the hallmarks of the morphology of basins in different regions and its distinctive features is the shape of the basin. This morphometric indicator is the analytical expression $L=f(F)$ that connects the basin's length with the area of the basin.[11-13] The total ratio of the length of the basin to the area of the basin is represented by the following general equation:

$$
L=K F^{n}
$$

where: $\mathrm{K}$ is the coefficient determining the shape of the basin; $n$-degree indicator.

Analysis of this equation (using data from Uzhydromet and R.G. Vafin [1]) showed that for intermountain rivers and streams in the territory of Uzbekistan, the correlation coefficient of the basin area and the length of the stream has a high correlation coefficient. 
(figure 5). The following are the equations of the connections of mountain rivers and streams and their coefficient correlations:

Mountain rivers

$$
L=2.39 F^{0.53}, \quad r=0.945
$$

Adir rivers

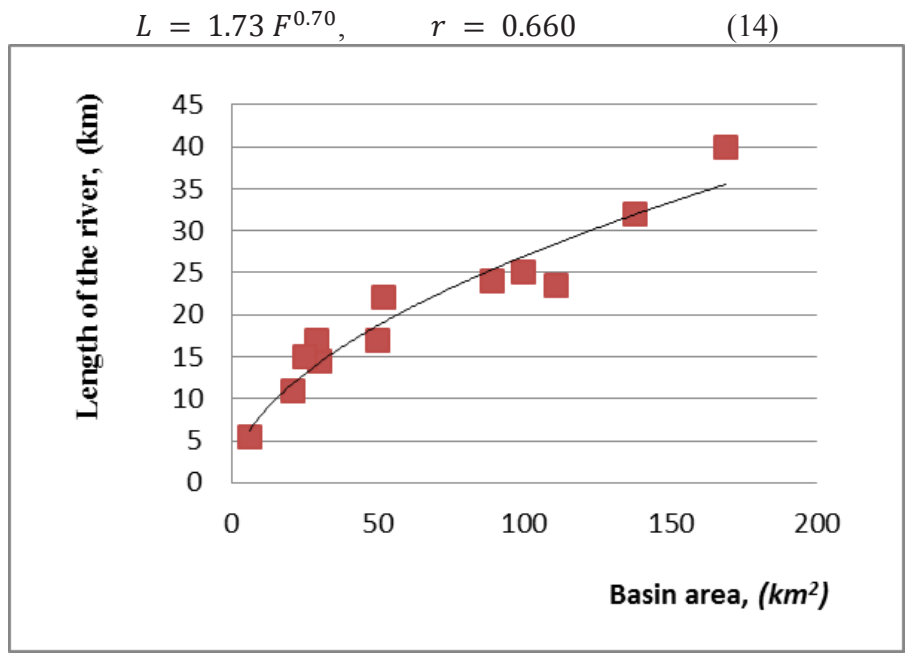

$a$

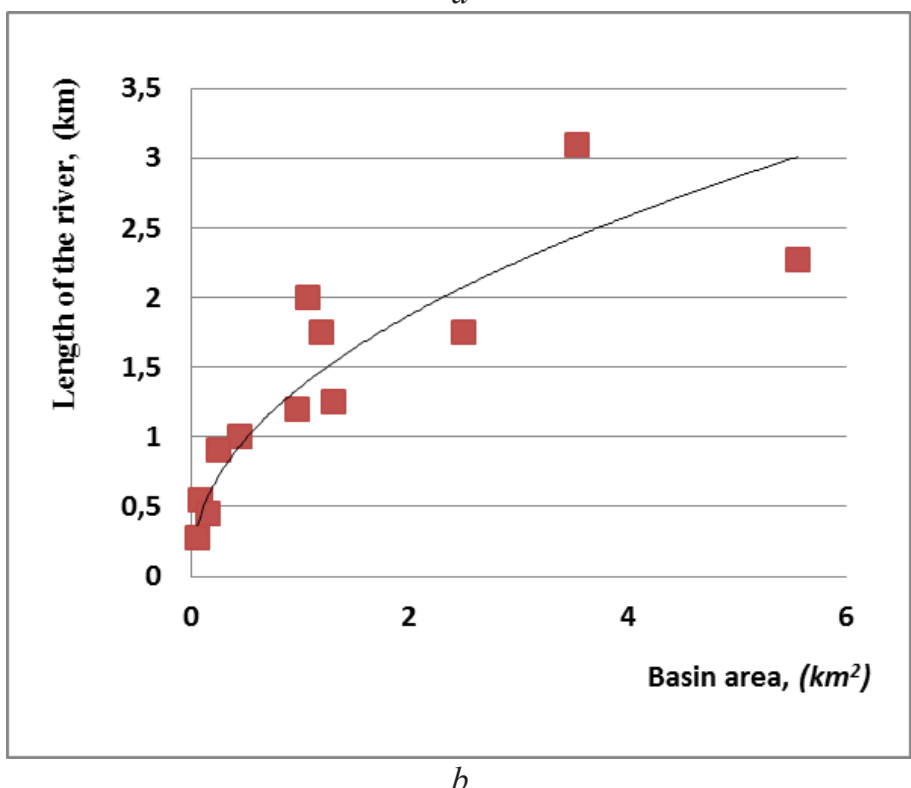




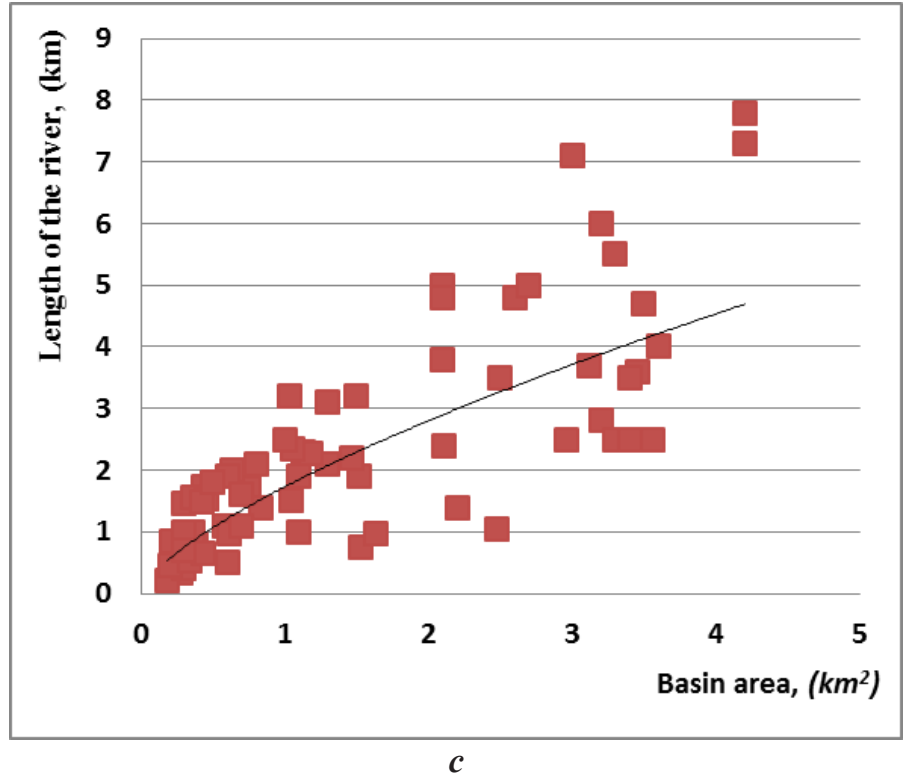

Fig. 5. Interrelation of foothills $(a)$ and Beshboz adyr rivers $(b)$ and Fergana, Andijan adyr rivers (c) with the basin area and the length of the basin in the territory of Uzbekistan

The parameters of the generated equations were compared with the values accepted by different scientists under different physiographic conditions (table 1). The results of the comparison showed that the parameters of the foothills of Uzbekistan differ from other physiographic regions, especially in the Adir rivers, where the coefficients of connection are small, and the correlation coefficients are high [14-16]

Determining the width of the river at maximum water consumption and its depth is described further. The calculated values of the width (V) and its depth (h) of the river or stream corresponding to the maximum flow rate can be determined using the hydromorphological connections of the river [17-20]

The existence of such hydromorphological connections for rivers and their analysis have been cited by scientists in the sources. The authors' research mentioned in the monograph [5] cover hydromorphological connections of rivers with constant flow, while the research of A.M.Muhamedov and H.A.Ismagilov [3] focus on these connections of mountain rivers with the medium and small temporary flow in Uzbekistan. 
Table 1 Water located in different physiographic regions and morphological indicators of basins

\begin{tabular}{|c|c|c|c|c|c|}
\hline № & $\begin{array}{l}\text { Physiographic } \mathrm{x} \\
\text { borders, rivers, } \\
\text { streams }\end{array}$ & $\begin{array}{l}\text { (12)number } \\
\text { coefficients, } K\end{array}$ & $\begin{array}{l}\text { (12) - expression } \\
\text { the degree } \\
\text { of age, } n\end{array}$ & $\begin{array}{c}\text { Corre } \\
\text { coefficient } \\
, r\end{array}$ & Author \\
\hline 1 & $\begin{array}{l}\text { All physiographic } \\
\text { areas }\end{array}$ & $1.50-2.50$ & $0.50-0.60$ & & I.F. Goroshkov \\
\hline 2 & $\begin{array}{l}\text { in the desert, desert- } \\
\text { forest regions of } \\
\text { Russia }\end{array}$ & $\begin{array}{l}1.80 \\
1.14\end{array}$ & $\begin{array}{l}0.50 \\
0.57\end{array}$ & & G.A. Alekseev \\
\hline 3 & $\begin{array}{c}\text { The foothills of } \\
\text { southeastern Nepal }\end{array}$ & 2.50 & 0.50 & & $\begin{array}{c}\text { B.F. } \\
\text { Perevoz-Nikov }\end{array}$ \\
\hline 4 & $\begin{array}{l}\text { Chirchik-Ahangaran } \\
\text { hydrological territory }\end{array}$ & 2.30 & & & Yu.M.Denisov \\
\hline 5 & Small rivers are born & 2.39 & 0.53 & 0.94 & $\begin{array}{c}\text { A.Kh. } \\
\text { Tulyaganov }\end{array}$ \\
\hline 6 & $\begin{array}{c}\text { Fergana and Andijan } \\
\text { Adir rivers }\end{array}$ & 1.73 & 0.70 & 0.66 & $\begin{array}{c}\text { A.Kh. } \\
\text { Tulyaganov }\end{array}$ \\
\hline 7 & Beshbuz Adir streams & 1.36 & 0.46 & 0.89 & $\begin{array}{c}\text { A.Kh. } \\
\text { Tulyaganov }\end{array}$ \\
\hline
\end{tabular}

R.G.Vafin (Uzgipravodkhoz), who conducted research in the analyzed areas, S.H. Based on the field materials of the Tulyaganov (Central Asian Research Institute of Engineers), we used the following expressions known in the literature to form the hydromorphological connections required for the design of aqueducts for Mountain Rivers and hills:

$$
\begin{aligned}
& \mathrm{B}=K_{1}\left(\frac{Q}{\sqrt{g^{J}}}\right)^{m} \\
& h=K_{2}\left(\frac{Q}{\sqrt{g \mathcal{g}}}\right)^{n}
\end{aligned}
$$

In expressions $\mathrm{V}$ is the width of the channel along with the observed flow level, $\mathrm{m}$; $\mathrm{h}$ is the average depth of the stream, m; Q is flood flow consumption, $\mathrm{m}^{3} / \mathrm{s}, \mathcal{J}$ is slope of the river; $K_{1}$ and $K_{2}$ are the coefficients determining the stability of coastal and riverbed soils, respectively; $\mathrm{m}$ and $\mathrm{n}$ are degree indicators; $\mathrm{g}$ is $9,81 \mathrm{~m}^{2} / \mathrm{s}$.

The correlation method was used to derive the expressions. The analysis involved field materials from 5 basins from the Aksay, Maylisay, Jeleksay, Sassiqsay, Jidasay, Kengsay, Chartaksay, Kuduksay, Girvansay, Shishaksay, Irvadansay, Otoparsay, and Andijan adyr rivers located in the Fergana Valley. The general data on the materials of the 35 field measurements used are given in table 2 .

Table 2. General data on hydraulic measurements for flood flow used in the analysis

\begin{tabular}{|c|c|c|c|c|}
\hline Total number & $\begin{array}{c}\text { Sel consumption, } \\
\mathrm{m}^{3} / \mathrm{sec}\end{array}$ & $\begin{array}{c}\text { The width of the } \\
\text { stream, } \mathrm{V} \mathrm{m}\end{array}$ & $\begin{array}{c}\text { Depth of flow, } \mathrm{h} \\
\mathrm{m}\end{array}$ & $\begin{array}{c}\text { The slope of } \\
\text { the river, } \mathcal{J}\end{array}$ \\
\hline 35 & $7-160$ & $7-38$ & $0.11-0.65$ & $0.009-0.046$ \\
\hline
\end{tabular}

The diagram of the relationship between the width of the river and the depth of the flow of small rivers and streams formed based on the given data and the flow of the river and the river's slope is shown in Figure 6, respectively. The mathematical expression for these links is as follows:

$$
\mathrm{B}=3.363\left(\frac{Q}{\sqrt{g^{J}}}\right)^{0.33}
$$




$$
h=0.070\left(\frac{Q}{\sqrt{g 7}}\right)^{0.34}
$$

The connections have a manoli correlation coefficient, respectively $\mathrm{r}_{\mathrm{h}}=0,614$ ва $\mathrm{r}_{\mathrm{b}}=$ 0,582 .

These connections, formed by A.M.Mukhammedov in our opinion, the main reason for this, as mentioned above, can be explained by the fact that the foothills and hillside rivers are not separated.

\section{Results and Discussion}

The comparison of the quantities of coefficients and degree indicators that determine the stability of the soil in the hydromorphological connections in the expressions (17) and (18) is of special importance for practice. Table 2 shows comparisons of indicative values of hydromorphological connections of rivers with constant flow and small foothills and adyr rivers (calculations on rivers with constant flow, including Syrdarya, Chirchik, Naryn, Sokh, and Chatkal rivers and their results H.A.Ismagilov [3]).

Analyzing the data presented in the table, it can be seen that the indicators of hydromorphological connections of open waters (rivers and streams) located in different regions and with different hydrological regimes are very close to each other; in some cases, the values $\left(\mathrm{K}_{1}, \mathrm{~h}\right)$ are the same. We see that the coefficient of stability of the bottom soils $\left(\mathrm{K}_{2}\right)$ is twice as small in the foothills and adyr rivers, where the flow of rainwater is observed, compared to rivers with a constant flow.

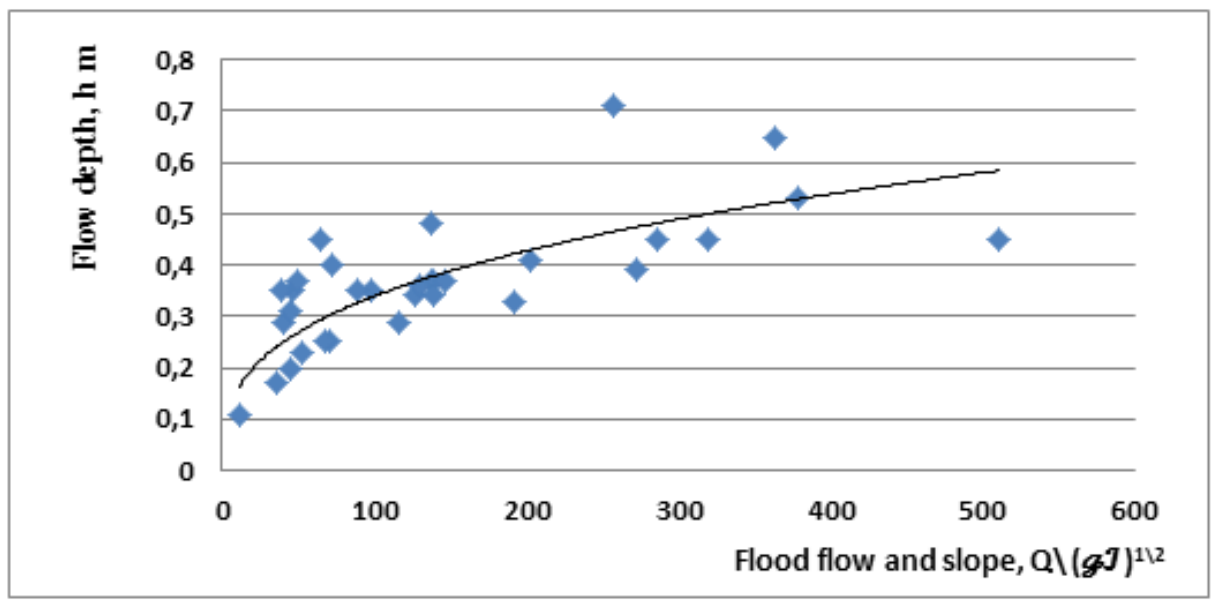




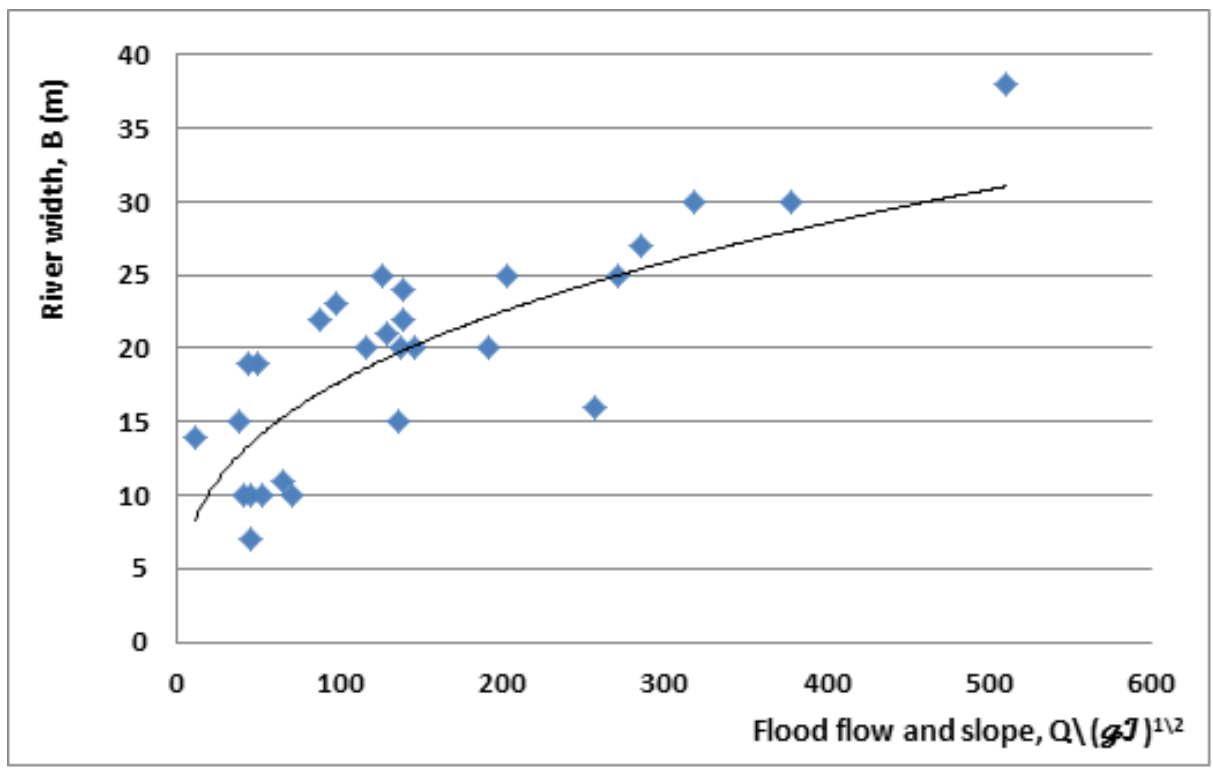

Fig. 6. Correlation of the width (left) and depth of the river (right) with the flow and slope of the foothills and hills along with the flow level

Table 3 Table comparing the coefficients and levels of hydro morphological bonds under different conditions

\begin{tabular}{|c|c|c|c|c|}
\hline Total number & $\begin{array}{c}\text { Sel consumption, } \\
\mathrm{m}^{3} \mathrm{sec}\end{array}$ & $\begin{array}{c}\text { The width of the } \\
\text { stream, } \mathrm{V} \mathrm{m}\end{array}$ & $\begin{array}{c}\text { Depth of flow, } \\
\mathrm{h}, \mathrm{m}\end{array}$ & $\begin{array}{c}\text { The slope of the } \\
\text { river, } \mathcal{J}\end{array}$ \\
\hline 35 & $7-160$ & $7-38$ & $0.11-0.65$ & $0.009-0.046$ \\
\hline
\end{tabular}

\section{Conclusions}

This situation can be explained by the fact that in the conditions of strong floods in the foothills and Adir streams, the banks of the morphometric or hydrometric storks are determined for the deformation (change) of the river and the flow measurement were selected from stable locations.

In order to assess the accuracy of the proposed hydro-morphological connections (expressions 17, 18) for the above foothills and adyr streams, the calculation results were compared with the measured quantities (taken from materials [2, 4] under different conditions not included in the analysis. These comparisons show that the proposed computational equations 17 and 18 are sufficient and satisfactory for practice.

\section{References}

1. Bulgakov N.P., Ryvina E.M., Fedotov G.A. Applied geodesy: Ucheb.dlya vuzov, p. 416, (1990)

2. Vafin R.G. Pavodki and selevye potoki in Uzbekistan, OJSC "U'ZSUVLOYIHA", p. 138, Tashkent, (2012)

3. Muhamedov A.M., Ismagilov X.A. Mutnost potoka vremennyx vodotokov, Reports VASXNIL, № 1, p. 36-38, (1981)

4. Tulaganov A.X., Tulaganov S.X. Flood hydrology and protection of highways from flood currents, Economy Assembly, p. 96, (2013) 
5. Tulyaganov A.X., Salimova B.D. Calculation of water and flood characteristics in the design of drainage structures on highways, Economy - Finance, p. 156 Tashkent, (2016)

6. Arifjanov A., Samiev L., Apakhodjaeva T., Qurbonov X., Yusupov Sh., Atakulov D. Processes of Mirishkor channel using GIS technologies, IOP Conference Series: Materials Science and Engineering, 918(1), (2020) DOI: 10.1088/1757899X/918/1/012143

7. Arifjanov A., Rakhimov K., Abduraimova D., Babaev A., Melikuziyev S. Hydrotransport of river sediments in hydroelelators, IOP Conference Series: Materials Science and Engineering, 869(7), (2020) doi: 10.1088/1757899X/869/7/072003

8. Arifjanov A., Fatxullaev A. Natural Studies for Forming Stable Channel Sections Journal of Physics: Conference Series, 1425(1), (2020), doi: 10.1088/17426596/1425/1/012025

9. Arifjanov A., Rakhimov K., Abduraimova D., Akmalov S. Transportation of river sediments in cylindrical pipeline, IOP Conference Series: Earth and Environmental Science, 403(1). (2019), doi: 10.1088/1755-1315/403/1/012154

10. Arifjanov A., Samiev L., Apakhodjaeva T., Akmalov S. Distribution of river sediment in channels. IOP Conference Series: Earth and Environmental Science, 403 (1), (2019), doi: 10.1088/1755-1315/403/1/012153

11. Arifjanov A., Akmalov S., Akhmedov I., Atakulov D. Evaluation of deformation procedure in waterbed of rivers, IOP Conference Series: Earth and Environmental Science, 403(1), (2019), doi: 10.1088/1755-1315/403/1/012155

12. Arifjanov A., Samiev L., Akmalov S. Dependence of fractional structure of river sediments on chemical composition, International Journal of Innovative Technology and Exploring Engineering, 9 (1), pp. 2646-2649, (2019), doi: 10.35940/ijitee.L2944.119119

13. Arifzhanov, A.M. Method for calculation of the distribution of drift particles in variable section beds (VSB), Gidrotekhnicheskoe Stroitel'stvo, (2), pp. 44-45, (2004)

14. Arifzhanov, A.M. Distribution of Suspended Sediment Particles in a Steady-State Flow, Water Resources, 28(2), pp. 164-166, (2001), doi: 10.1023/A:1010375500148

15. Samiyev L., Allayorov D., Atakulov D., Babajanov F. The influence of sedimentation reservoir on hydraulic parameters of irrigation channels, IOP Conference Series: Materials Science and Engineering, 883(1), (2020) doi: 10.1088/1757899X/883/1/012031

16. Fatxulloyev A., Abduraimova D., Otakhonov M., Atakulov D., Samiev L. Method designing of open drainages IOP Conference Series: Materials Science and Engineering, 883(1), (2020), doi: 10.1088/1757-899X/883/1/012047

17. Abduraimova D., Atakulov D., Ibragimova Z., Apakhodjaeva T. Evaluation of erosion and accumulative process with using Geoinformation systems in water resource management International Conference on Information Science and Communications Technologies: Applications, Trends and Opportunities, ICISCT (2019), DOI: 10.1109/ICISCT47635.2019.9012020

18. Muratov A., Muratov O., Melikuziyev S. Operational control of energy consumptions of reclamation machines, IOP Conference Series: Earth and Environmental Science, 614(1), (2020) doi: 10.1088/1755-1315/614/1/012042 
19. Muratov A., Melikuziev S. Technology of formation of combined products of meliorative purpose IOP Conference Series: Materials Science and Engineering, 883(1), (2020), doi: 10.1088/1757-899X/883/1/012060

20. Lee A., Usmonov T., Norov B., Melikuziev S. Advanced device for cleaning drain wells, IOP Conference Series: Materials Science and Engineering, 883 (1), (2020), doi: 10.1088/1757-899X/883/1/012181 